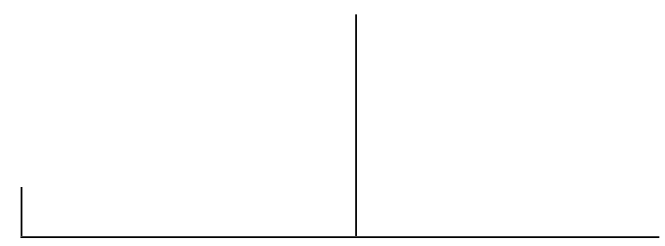

Rev. Latinoam. Psicopat. Fund., São Paulo, v. 12, n. 2, p. 276-284, junho 2009

\title{
Falhas na operação transitivista materna na síndrome de Münchhausen por procuração
}

Adela Stoppel de Gueller

A síndrome de Münchausen por procuração (Münchhausen syndrom by Proxy - MSBP), incluída desde 1980 no DSM-III, se configura quando uma pessoa próxima da criança (na grande maioria dos casos, a mãe) sugere ou produz signos falsos para que ela seja examinada por médicos. O presente artigo propõe uma leitura dessa configuração desde a perspectiva psicanalítica. Trabalha-se com a hipótese de tratar-se de um quadro ocasionado por uma falha na operação transitivista materna.

Palavras-chave: Síndrome de Münchhausen por procuração, transitivismo, relação mãe-filho, psicanálise 
O modelo original dessa relação de dependência entre aquele que vai se tornar vítima e aquele que vai abusar de sua força encontra-se na relação entre a mãe e o filho pequeno. Se o choro deste, quando a alerta e ela a ele responde com eficácia, constitui a matriz da troca humana e o ponto de partida dos motivos morais, não é precisamente porque está em seu temível poder ignorá-lo?

Sophie de Mijolla-Mellor

Tem-se dado pouca atenção, no âmbito "psi”, à síndrome de Münchhausen ${ }^{1}$ por procuração (MSBP), apesar de estimar-se que até $2 \%$ dos pacientes internados em hospitais pediátricos se possam classificar nesse quadro.

Ela consta no DSM-III desde 1980 na categoria dos transtornos factícios ou fictícios e se configura quando uma pessoa próxima da criança (na grande maioria dos casos, a mãe) sugere ou produz signos falsos, induzindo a medicina a investigar a criança. A síndrome é situada junto dos simuladores, mas se distingue deles por não haver uma clara motivação como a evasão de um processo criminal ou do recrutamento militar, a obtenção de moradia ou de drogas ou a compensação financeira. A única motivação atualmente aceita que é compatível com o diagnóstico de Münchhausen é a de querer ocupar o papel de doente.

Não soa estranho que alguém queira ocupar o lugar de paciente. Um pouco mais difícil é aceitar que, para isso, se faça objeto de complexos e dolorosos exames médicos. Mesmo assim, é possível pensar no masoquismo erógeno ou no masoquismo moral. Mas transferir essa posição ao filho levanta uma série de perguntas. É o masoquismo transferível? Trata-se de uma reversão para o sadismo? Em todo caso, já que se pode traduzir by proxy por "transferido" ou "delegado", podemos nos perguntar: o que e a quem a mãe estaria transferindo ou delegando?

1. Essa denominação refere-se ao clássico personagem da literatura alemã conhecido pelos relatos hiperbólicos e fantasiosos que fazia de suas façanhas (Burger, 1990). 


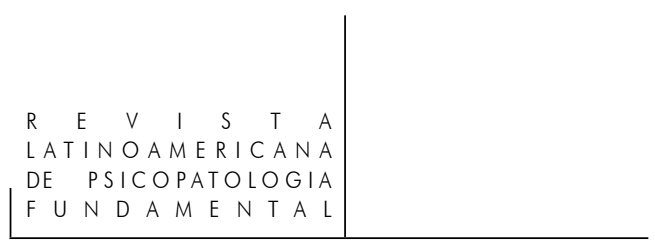

Os médicos se questionam, se culpam e encolerizam perante esses casos que contrariam o amor materno. Lembremos que ainda, na edição de 1971 da Larousse, descreve-se o instinto materno como "uma tendência primordial que cria em toda mulher normal um desejo de maternidade e que, uma vez satisfeito esse desejo, incita a mulher a zelar pela proteção física e moral dos filhos" (apud Badinter, 1985, p. 71).

Mas, dado o amor materno como um instinto, também se pode definir sua perversão - o desvio ou a ausência do que se considera normal e natural para toda mulher. É nessa perspectiva que se situa a MSBP. Ao descrevê-la inicialmente, Meadow destacou na mãe uma motivação sádica, supondo que ela esperasse que se aplicassem procedimentos cruéis à criança. ${ }^{2}$

Contudo, quando o quadro passou da pediatria para os manuais de psiquiatria (DSM-4 e CID-10), alegou-se que a motivação da mãe seria querer ocupar indiretamente o papel de doente, e, assim, a eventual crueldade dos procedimentos passou a ser secundária.

Afirmar sem outro questionamento que o objetivo da mãe passou a ser tornar-se indiretamente objeto de cuidados não implica restringir-se ao benefício secundário do sintoma e desconsiderar o primário? ${ }^{3}$ O que há por trás desse modo de proceder ou, dito de outro modo, que tipo de satisfação primária a mãe obtém dessa maneira?

Em torno dessa questão, tentaremos traçar alguns dos pontos que nos parecem centrais na MSBP. Para tanto, recorreremos ao conceito de transitivismo tal como trabalhado por Bergès e Balbo (2002), o que nos permitirá analisar o tipo de falha que se estabelece nesse quadro no vínculo entre a mãe e o filho e propor uma hipótese sobre o que poderia ocasionar um tal procedimento (Bergès; Balbo, 2002).

Inicialmente trabalhado por Wallon, o conceito de transitivismo descreve um momento anterior à individuação. Trata-se daquele momento em que um sujeito se machuca e outro sofre. Em As origens do caráter na criança, Wallon (1934) o situa no estágio de personalidades intercambiáveis. Ele entende que o sujeito se faz substituir por outro a ponto de este se instituir em seu lugar, devido à indiscriminação do tipo primitivo de relação entre o sujeito e o outro.

2. Vale a pena notar que, mesmo assim, em muitos casos, não se trataria de um sadismo exercido de modo direto, mas através da equipe médica que realizaria esses procedimentos.

3. Lembremo-nos de que Freud definia o benefício secundário como a vantagem suplementar ou a utilização obtida pelo sujeito a partir de uma doença já construída, implicando uma mudança vantajosa das relações com o meio, enquanto o benefício primário seria aquele que entra na conta na própria motivação de uma neurose pela satisfação libidinal encontrada no sintoma. 
Wallon retirou do transitivismo o caráter patológico dado anteriormente por Wernicke ${ }^{4}$ e situou-o como um estágio normal do desenvolvimento.

Bergès e Balbo (2002) ampliaram o conceito de transitivismo ao mostrar o papel fundamental que a mãe tem na "operação transitivista", operação que possibilita à criança simbolizar a dor corporal. Sabemos a importância que tem na relação mãe-filho a nomeação por parte da mãe do que ela supõe que se passa com o filho. Sabemos quanto é constitutivo que a mãe lhe diga "sua barriguinha está doendo" ou, se o filho cai, quão importante é o gesto de dor da mãe, que, juntamente com as palavras "ai! vamos passar uma aguinha", determinam que ele chore, se angustie ou se acalme. Esse ato de nomeação viabiliza, para a criança, a entrada no mundo simbólico, porque ela precisa se identificar com o discurso da mãe levando em conta os afetos que ela nomeia para poder designar suas próprias experiências. Isso quer dizer que as experiências que ela vive com seu corpo precisam passar pela referência e pela nomeação das experiências da mãe. Por isso podemos afirmar que é no outro com quem o sujeito se identifica que ele se experimenta inicialmente. É na troca com o outro que o sujeito se apreende como corpo.

Segundo Bergès e Balbo (2002), a operação transitivista da mãe se faz sobre uma dupla negação: a criança que cai não reage (primeira negação) e a mãe que se queixa de ter sofrido o golpe não o sofreu (segunda negação). Mas a mãe constrange de alguma maneira o filho a avaliar o que ele experienciou referido a seu próprio sofrimento. Os mesmos autores falam na "forçagem" (2002, p. 19) que o pensamento transitivista opera nesse movimento, que está muito longe dos suaves cuidados maternais, já que a mãe nega o que seu filho realmente experiencia e o força a experimentar em espelho o que ele deve experienciar. Normalmente, essa forçagem não é traumática e implica simplesmente a entrada no campo da linguagem e da fala. $\mathrm{O}$ outro da criança a obriga a sofrer o que ela não experienciou, em nome e por amor ao lugar constitutivo que ocupa para ele. "O dizer da mãe, ao substituir o sofrimento que ela supõe ter sido experienciado pelo filho, torna simbólico esse sofrimento; é nesse sentido que a fala da mãe é recalcante e impõe limites" (Bergès; Balbo, 2002, p. 25).

À diferença do que acontece normalmente, quando uma mãe supõe que seu filho está doente ou machucado, na MSBP, os sintomas são fabricados, e isso se faz de três modos: a) com relatos falsos (nos casos mais leves); b) alte-

4. Wernicke (apud Cheniaux, 2008) definia o transitivismo como uma alteração da consciência dos limites do eu em que o indivíduo atribui a uma outra pessoa ou a um animal vivências que na verdade são suas - como sentimentos, pensamentos ou alucinações.

Rev. Latinoam. Psicopat. Fund., São Paulo, v. 12, n. 2, p. 276-284, junho 2009 


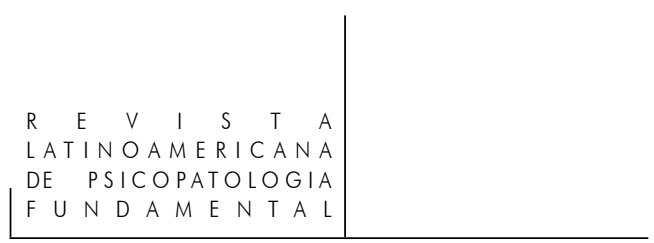

rando-se material de laboratório; ou c) provocando sintomas no corpo da criança. A suposição de um saber inconsciente do filho por parte da mãe não se produz e transfere-se diretamente para o médico, daí a demanda se endereçar a ele. O filho parece ser o veículo (objeto) para que a mãe transfira o lugar de doente dela para ele. ${ }^{5}$

Assim, a mãe faz uma demanda dupla: há um pedido de atenção transferido dela para o filho e um pedido de nomeação do que se passa com o filho. O pedido de atenção se realiza. A mãe vai de hospital em hospital, às vezes mudando de cidade e mudando também a descrição clínica do quadro. A criança é internada para ser examinada e tratada, e a mãe quando começa a desconfiar que suspeitam dela, solicita a alta. É por isso que o quadro é caracterizado como uma compulsão e é nesse nível que podemos situar o objetivo alegado no DSM-IV e no CID-10 - tornar-se indiretamente objeto de cuidados. Mas o pedido de nomeação, que acreditamos devesse situar-se num outro nível, falha, porque as pistas falsas não permitem chegar ao diagnóstico.

Num outro momento, consideramos essa demanda como um pedido de acolhimento da mãe, tendo em vista que o hospital se configura na atualidade como um lugar de acolhimento social (Gueller, 2006). Consideramos também que pedir acolhimento dessa forma suponha um fracasso do laço simbólico que une a mãe ao filho. Esse fracasso, que se manifesta como demanda de diagnóstico, se expressa no pedido de nomeação. O que meu filho tem? O que meu filho é? Mesmo sabendo que não se trata disso, a mãe apela para um saber e pede um nome e um tratamento para o filho. Supomos, pois, que haja nessa demanda algo verdadeiro que a mãe está pedindo, embora ela não saiba o que é.

No exemplo que Wallon toma de E. Köheler e tornou-se clássico para ilustrar o transitivismo, ele relata uma cena em que uma menina de dois anos e nove meses a que chama A. está sentada entre sua governanta e uma amiguinha $\mathrm{H}$. Inquieta e atormentada por um desejo, A. golpeia bruscamente e empurra $\mathrm{H}$. "O que fazes?", pergunta a governanta. "H. é má, acaba de bater em mim", responde A. A governanta replica: "Não, ela está quietinha!". Vê-se então que a menina atribui a agressão à amiga e assim alivia sua angústia, mostrando a indiferenciação entre o sentimento e o gesto que dele resulta. Só a posteriori poderá discernir entre si mesma e o partenaire, ajudada pela intervenção da governanta.

5. Essa hipótese coincide parcialmente com a levantada por Zenoni (2002). Para o autor, trata-se de um quadro de psicose da mãe, o que explicaria melhor o "imotivado" dos comportamentos que ele considera passagens ao ato. Pensamos, no entanto, que essa generalização não permite prestar a devida atenção a variantes importantes que vão desde a provocação de sintomas no corpo da criança a relatos falsos de sintomas, ou seja, as diferenças que há entre a passagem ao ato e o acting out.

Rev. Latinoam. Psicopat. Fund., São Paulo, v. 12, n. 2, p. 276-284, junho 2009 


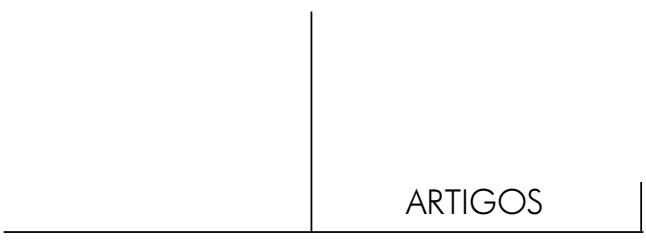

As crianças pequenas repetem essas situações uma e outra vez, justapondo-as, sem relacioná-las nem integrá-las num sentimento de responsabilidade pessoal, como se não tivesse havido arrependimento. Por isso, a crueldade das crianças decorre da indiferenciação, da ignorância do outro, que se confundem com insensibilidade. Parece-nos que na síndrome de Münchhausen por procuração se produz uma situação análoga, só que a mãe não é uma criança. Wallon afirma que, quando essas situações se apresentam no adulto, evidenciam um desfalecimento da atividade psíquica. Falta, pois, um adulto que nomeie, limite e diferencie os sujeitos em questão, e parece ser nesse vácuo aberto pela falha simbólica do discurso materno que se produz a transferência da mãe para a equipe médica. A relação dual sujeito-objeto convoca uma instância terceira. A suposição de um saber inconsciente da criança se transfere para os médicos e se expressa como demanda de conhecimentos científicos. No lugar da identificação da mãe com a criança, o endereçamento aos médicos transfere o poder de nomeação e afetação da mãe para o corpo técnico. E, como numa espécie de rebote, o "ai" que se espera da mãe passa a ser esperado daquele que atende a criança. Mas será que a criança poderá se identificar com essa instância? Aí, só se podem dar respostas caso a caso, mas vale a pena sublinhar que, se falamos na forçagem que usualmente opera o discurso transitivista materno, introduzindo a criança no campo da fala e da linguagem, podemos afirmar que a ausência desse discurso é violenta e cruel, já que a criança não tem com o que proceder a uma elaboração simbólica da dor e fica mergulhada num masoquismo real.

Sabe-se muito pouco sobre as consequências psíquicas da MSBP nas crianças. Os casos diagnosticados se ocupam fundamentalmente da mãe, encaminhando-a para um tratamento psicoterápico que costuma fracassar e, em alguns casos, a derivação à Vara da Infância determina a separação da mãe e da criança. Meadow informou que as crianças que foram retiradas de seu lar e separadas da mãe mantinham atitudes evitativas, alterações do sono, comportamentos hipocondríacos e síndrome de estresse pós-traumático.

Um estudo retrospectivo sobre 47 mães nos informa que $72 \%$ tinham uma história de transtornos fictícios ou somatomorfos, 55\% tinham na sua história episódios de autoagressão e nenhuma tinha apresentado episódios psicóticos (Bools; Neale; Meadow, 1994, p. 773-788).

A partir da relação que estabelecemos com o transitivismo, pensamos que devemos aprofundar o questionamento sobre o gozo masoquista, que seria a satisfação primária obtida pela mãe. Bergès e Balbo (2002) afirmam que a operacão transitivista da mãe é fundamental na constituição do masoquismo primário da criança. Quando a mãe diz "ai, como dói”, ao ver seu filho cair, o que se transitiva não é a dor, mas o masoquismo, já que a mãe não está experimentando dor, mas um certo gozo. Assim, a função da operação transitivista materna seria li- 


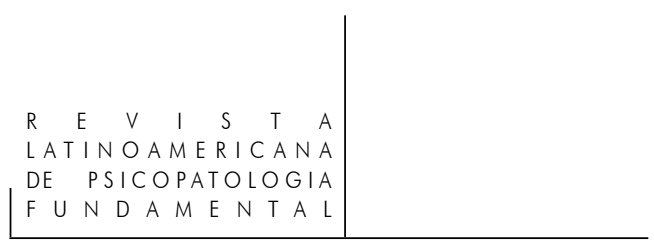

mitar o masoquismo do outro, e não sua dor. Os autores acreditam ainda que a dor seja secundária à satisfação masoquista e já resultado de uma elaboração simbólica. Nesse sentido, consideram que a dor esperaria ser dita para ser experimentada, e que a criança se apropriaria do saber que a mãe lhe transmite sobre a dor para senti-la.

Seguindo essa hipótese, podemos pensar que, nesse quadro em que o transitivismo se apresenta como patológico, o masoquismo não limitado da mãe procura, através da fabricação de sintomas no filho, que a equipe médica descubra o procedimento para frear o gozo masoquista de que ela goza indiferenciadamente com seu filho. Sua impossibilidade de estabelecer um laço simbólico com o filho e se deixar afetar por ele a levam a fabricar sintomas, à espera de que alguém não só possa dar nome como também sentir a dor que ela não sente com a criança transitivista. A função recalcante e limitadora que a nomeação tem recairia, pois, sobre o corpo médico, sempre que, ao investigar sintomas que foram provocados como signos falsos, o médico não crie uma verdadeira doença como a iatrogenia.

\section{Referências}

Ascher, R. Munchausen's syndrome. Lancet, v. 1, p. 339-341, Feb. 1951.

BADINTER, E. Um amor conquistado: o mito do amor materno. Rio de Janeiro: Nova Fronteira, 1985.

Barnetche Barth, L. F.; Fernandes Silveira, V. O transitivismo como dispositivo clínico-conceitual. Disponível em: <http://www.scielo.br/pdf/agora/v7n2/ v7n2a05.pdf>. Acesso em: 27 jul. 2008.

Bergès, J.; Balbo, G. A criança e a psicanálise. Porto Alegre: Artes Médicas, 1997. . Jogo de posições da mãe e da criança: ensaio sobre o transitivismo. Porto Alegre: CMC, 2002.

Bools, C.; Neale, B.; Meadow, R. Münchausen Syndrome by proxy: a study of psychopatology. Child abuse Negl, v. 18, n. 9, p. 773-788, Sep. 1994.

Burger, G. A. As aventuras do Barão de Münchausen. Belo Horizonte: Vila Rica, 1990.

Cheniaux, E. Psicopatologia descritiva: existe uma linguagem comum. Revista Brasileira de Psiquiatria, v. 27, n. 2, p. 157-162, 2005. Disponível em: <http:// www.scielo.br/pdf/\%0D/rbp/v27n2/a17v27n2.pdf>. Acesso em: 21 dez. 2008.

Freud, S. (1924). El problema económico del masoquismo. In: Obras Completas. Buenos Aires: Amorrortu, 1996. v. 19.

Rev. Latinoam. Psicopat. Fund., São Paulo, v. 12, n. 2, p. 276-284, junho 2009 


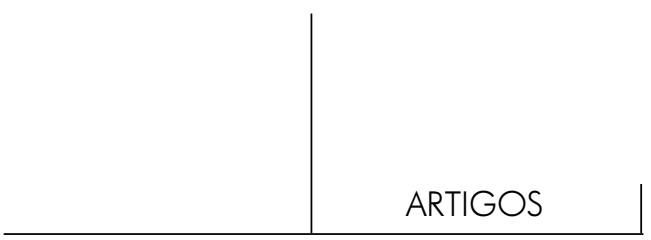

GuEller, A. J. S. Entre a mãe ideal e a medicina ideal: síndrome de Münchhausen transferida, um transtorno factício. Latin American Journal of Fundamental Psychopathology online, v. 6, p. 56-68, 2006.

LACAN, J. El estadio del espejo como formador de la función del yo (je) tal como se nos revela en la experiencia psicoanalítica. In: Escritos. México, DF: Siglo XXI, 1984.

MeAdow, R. Münchhausen syndrome by proxy. Arch Dis Child, v. 57, n. 2, p. 92-98, Feb. 1982.

Mijolla-Mellor, S. (Org.). Crueldade no feminino. Rio de Janeiro: Companhia de Freud, 2005.

Rosenberg, D. A. Web of deceit: a literature review of Münchhausen syndrome by proxy. Child Abuse Negl, v. 11, n. 4, p. 547-563, 1987.

Wallon, H. (1934). Los orígenes del carácter en el niño. Buenos Aires: Lautaro, 1965.

Zenoni, A. Quando o filho realiza o objeto (a respeito da chamada "síndrome de Münchhausen por procuração”). Psicologia em Revista, Belo Horizonte, v. 8, n. 12, p. 65-71, dez. 2002.

El síndrome de Münchhausen por poder (Münchhausen syndrom by Proxy-

(Fallas en la operación transitivista materna en el síndrome de Münchhausen por MSBP), incluido desde 1980 en el DSM-III, se configura cuando una persona próxima al niño (en la mayoría de los casos, la madre) sugiere o produce signos falsos para que él sea examinado por médicos.El presente artículo propone una lectura de esta configuración desde la perspectiva psicoanalítica. Se trabaja con la hipótesis de que se trata de un cuadro ocasionado por una falla en la operación transitivista materna. Palabras claves: Síndrome de Münchhausen por poder, transitivismo, relación madre-hijo, psicoanálisis

(La faillite de la fonction transitiviste dans le syndrome de Münchhausen par procuration)

Le syndrome de Münchhausen par procuration (Münchhausen syndrom by ProxyMSBP), inclus dans le DSM-III depuis 1980, se configure quand une personne proche de l'enfant (en général la mère) suggère ou produit de faux signes pour que celui-ci soit examiné par le corps médical. Cet article propose une lecture de cette configuration du point de vue de la psychanalyse. Il développe l'hypothèse d'un tableau clinique provoqué par une faille de la position transitiviste chez la mère.

Mots clés: Syndrome de Münchhausen par procuration, transitivisme, relation mèreenfant, psychanalyse

Rev. Latinoam. Psicopat. Fund., São Paulo, v. 12, n. 2, p. 276-284, junho 2009 


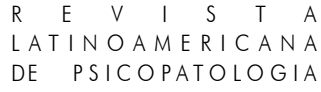

(Failings in maternal transitivist operation in the Münchhausen syndrome by proxy)

The Münchhausen syndrome by proxy (MSbP), included in the DSM-III since 1980, consists of behaviors whereby a person who is close to a child (almost always the mother) suggests or feigns false signs in order to have the child submitted to medical examination. The present article proposes a reading of this configuration from a psychoanalytic perspective. The basic hypothesis is that this disorder is produced by failings in the mother's operation of transitivism.

Key words: Münchhausen syndrome by proxy, transitivism, mother-child relation, psychoanalysis

Citação/Citation: Gueller, A. S. Falhas na operação transitivista materna na síndrome de Münchhausen por procuração. Revista Latinoamericana de Psicopatologia Fundamental, São Paulo, v. 12, n. 2, p. 276-284, jun. 2009.

Editor do artigo/Editor: Prof. Dr. Manoel Tosta Berlinck.

Recebido/Received: 11.9.2008 / 9.11.2008 Aceito/Accepted: 18.12.2008 / 12.18.2008

Copyright: (C) 2009 Associação Universitária de Pesquisa em Psicopatologia Fundamental/ University Association for Research in Fundamental Psychopathology. Este é um artigo de livre acesso, que permite uso irrestrito, distribuição e reprodução em qualquer meio, desde que $\mathrm{o}$ autor e a fonte sejam citados/This is an open-access article, which permits unrestricted use, distribution, and reproduction in any medium, provided the original author and source are credited.

Financiamento/Funding: $\mathrm{O}$ autor declara não ter sido financiado ou apoiado/The author has no support or funding to report.

Conflito de interesses: $\mathrm{O}$ autor declara que não há conflito de interesses/The author declares that has no conflict of interest.

Adela Stoppel de Gueller

Psicanalista; doutora em Psicologia Clínica pela Pontifícia Universidade Católica de São Paulo - PUC-SP (São Paulo, Brasil); professora do curso de especialização Psicologia Clínica Teoria Psicanalítica, na Pontifícia Universidade Católica de São Paulo - Coordenadoria Geral de Especialização, Aperfeiçoamento e Extensão - PUC-COGEAE (São Paulo, Brasil); coordenadora do Curso de Psicanálise da Criança, no Instituto Sedes Sapientiae (São Paulo, Brasil).

R. Ministro Godoy, 1.484

05015-900 São Paulo, SP, Brasil

e-mail: adela@gueller.com.br

Rev. Latinoam. Psicopat. Fund., São Paulo, v. 12, n. 2, p. 276-284, junho 2009 